\title{
Analysis of Helicobacter pylori vacA and cagA genotypes and serum antibody profile in benign and malignant gastroduodenal diseases
} D Basso, F Navaglia, L Brigato, M G Piva, A Toma, E Greco, F Di Mario, F Galeotti,
G Roveroni, A Corsini, M Plebani

\begin{abstract}
Background-Helicobacter pylori species comprise different strains, cytotoxic and non-cytotoxic, which can be identified on the basis of their genomic pattern.

Aims-(1) To evaluate the polymorphism of the $v a c A$ gene and to ascertain whether the $\operatorname{cag} A$ gene is present in patients with gastric adenocarcinoma. (2) To study the anti-H pylori antibody profile using western blotting.

Patients-Twenty one patients with gastric adenocarcinoma and 71 with $H$ pylori associated benign disease (nine gastric ulcer, 29 duodenal ulcer, 25 antral gastritis, and eight duodenitis).

Methods-The polymerase chain reaction was used to verify the presence or absence of $\operatorname{cag} A$ and to study the polymorphism of $v a c A$ in gastric mucosal samples obtained during endoscopy for patients with benign diseases and at surgery for patients with gastric adenocarcinoma. Fasting sera were used to assess anti-H pylori antibodies against different $H$ pylori antigens by western blotting.

Results-cagA gene and the allele s1 of vac $A$ were significantly less frequent in patients with antral gastritis $(60 \%$ and $60 \%)$ compared with patients with gastric adenocarcinoma $(94 \%$ and $100 \%)$ and with other non-malignant gastroduodenal diseases $(93 \%$ and $87 \%) \quad\left(\chi^{2}=16.01, p<0.001\right.$; and $\left.\chi^{2}=13.97, \mathbf{p}<0.01\right)$. In patients with gastric adenocarcinoma, antibodies against a 74 kDa $H$ pylori antigen were less frequently found than in patients with benign diseases.

Conclusions-H pylori infection caused by $\operatorname{cag} A$ positive/vac $A$ s1 strains is a frequent finding in patients with gastric adenocarcinoma. Prospective studies are needed to confirm whether the low incidence of positive serological response to the $74 \mathrm{kDa} H$ pylori antigen in patients with gastric adenocarcinoma is important. (Gut 1998;43:182-186)
\end{abstract}

Keywords: Helicobacter pylori; western blot; cagA; vacA; gastric adenocarcinoma

Epidemiological studies on large series show that Helicobacter pylori is a group 1 carcinogen for gastric adenocarcinoma, which is one of the most frequent cancers worldwide, the odds ratio for developing gastric cancer being 3.8 to 8.7 in $H$ pylori infected subjects. ${ }^{1-9}$ The pathophysiological mechanism by which $H$ pylori could lead to gastric cancer has not yet been defined, although many hypotheses have been put forward. ${ }^{15 \text { 8-14 }}$ It has been suggested that $H$ pylori may favour the transformation of normal mucosal cells into cancer cells as it promotes cell replication and also chronic mucosal inflammation with a wide polymorphonuclear infiltrate. $^{15-18}$ Furthermore the reduced mucosal ascorbic acid content and increased lipid peroxidation present in $H$ pylori infected patients may contribute to gastric carcinogenesis. ${ }^{19-21}$

$H$ pylori infection can also cause gastric and duodenal ulcer, type B chronic gastritis, and gastric MALToma. ${ }^{22-24}$ The wide spectrum of diseases associated with $H$ pylori infection may depend on the heterogeneity of $H$ pylori, and/or the heterogeneity of the host response to the same $H$ pylori strain.

Of the two main $H$ pylori strains, type I produces a vacuolating cytotoxin, whereas type II usually does not. ${ }^{25}$ The genome of almost all type I strains has a gene coding for CagA, a highly immunogenic, high molecular weight protein, which is not present in most type II strains. The gene coding for the vacuolating cytotoxin, vacA, is polymorphic and present in all strains. The polymorphism of vacA, mainly located in the region coding for the signal peptide (s) and in the mid portion of the gene (m), accounts for the phenotypic differences between type I and type II strains: both types synthesise a VacA protein, which is active as a vacuolating cytotoxin in type I, and inactive in type II strains. ${ }^{25} 26$

The immunological host response to $H$ pylori infection is characterised by the production of antibodies, which are easily detected in sera. Currently available methods, which use antigen preparations derived from sonicated or lysed bacteria, enable the detection of serum antibodies against a pool of $H$ pylori antigens. ${ }^{241827}$ More recently, the immunological response towards the CagA protein has been assayed using enzyme linked immunosorbent assay (ELISA) procedures. ${ }^{12-142528}$ However, little is known about the serological response to the different $H$ pylori antigens in patients with benign or malignant gastroduodenal $\mathrm{H}$ pylori associated diseases.

Our aims were therefore: (1) to evaluate the frequency of $\operatorname{cag} A$ and of the alleles $\mathrm{s} 1, \mathrm{~s} 2, \mathrm{~m} 1$, and $\mathrm{m} 2$ of vacA in patients with gastric adenocarcinoma, comparing findings with those in control patients with benign gastroduodenal diseases; and (2) to study, in the same patients, the anti- $H$ pylori antibody profile using western blotting. 


\section{Materials and methods}

In total, 92 patients from the north east of Italy were enrolled in the study. Of these, 21 (13 men, eight women; aged 31-84 years) had gastric adenocarcinoma (located in the upper third of the stomach in four, in the middle third in nine, and in the lower third in eight patients). Tumours were stage I in three cases, stage II in two, stage III in 12, and stage IV in four. In all patients a histological confirmation of the diagnosis of adenocarcinoma was obtained using samples taken intraoperatively. Two tissue samples, obtained from the neoplastic area and from the adjacent (at least $3 \mathrm{~cm}$ ) non-neoplastic mucosa, were stored at $-80^{\circ} \mathrm{C}$ until DNA extraction. Gastric juice was not available for these patients.

The reference controls were 71 patients with benign gastroduodenal diseases, chosen on the basis of the presence of $H$ pylori (histological assessment by staining with Giemsa and/or Whartin Starry); all underwent upper gastrointestinal endoscopy. The diagnoses, made on the basis of clinical history and endoscopic and histological findings, were: benign gastric ulcer (nine patients: seven men, two women; aged 44-73 years); duodenal ulcer (29 patients: 18 men, 11 women; aged 27-72 years); antral gastritis (25 patients: 11 men, 14 women; aged 28-79 years); and duodenitis (eight patients: seven men, one woman; aged range 24-70 years). Gastric and duodenal ulcers were noted at endoscopy; the benign nature of the gastric ulcers was confirmed by the histological assessment of biopsy specimens (8-10) taken at the ulcer margin. The patients with duodenitis had endoscopic findings of diffuse erythema, oedematous folds, friability, and erosions of the duodenum, but they did not have ulcers. Antral gastritis was histologically diagnosed ${ }^{18}$ and was present in almost all patients with $H$ pylori associated benign gastroduodenal diseases. The 25 patients classified as having antral gastritis had no visible pathology; they had microscopic antral gastritis only.

The patients with benign gastroduodenal diseases underwent upper gastrointestinal endoscopy during which a gastric juice sample and six antral and four body biopsy specimens were taken. Gastric juice was stored at $-20^{\circ} \mathrm{C}$ until DNA extraction, while the mucosal biopsy specimens were fixed in formalin and embedded in paraffin wax. Two antral and two body specimens were stained with haematoxylin and eosin for the microscopic evaluation of gastritis; the remaining four antral and two body specimens were stained with Giemsa

Table 1 cagA gene and vacA polymorphism in patients with benign gastroduodenal diseases or gastric adenocarcinoma. All patients had positive results for ure $A$ gene

\begin{tabular}{lcccccc}
\hline & & & \multicolumn{5}{l}{ vacA alleles (\% positive) } & \\
\cline { 6 - 7 } Diagnosis & Natients & $\begin{array}{l}\text { Per cent } \\
\text { cagA positive }\end{array}$ & \multicolumn{1}{l}{$s 1$} & $s 2$ & $m 1$ & $m 2$ \\
\hline Benign diseases & & & & & & \\
Antral gastritis & 25 & $60 \star \star \star$ & $60^{\star \star}$ & $40^{\star \star}$ & $32^{\star}$ & $68^{\star}$ \\
Gastric ulcer & 9 & 100 & 100 & 0 & 89 & 11 \\
Duodenal ulcer & 29 & 90 & 83 & 17 & 55 & 45 \\
Duodenitis & 8 & 100 & 88 & 12 & 63 & 37 \\
Malignant disease & 17 & 94 & 100 & 0 & 59 & 41 \\
Gastric adenocarcinoma & 17 & & & &
\end{tabular}

${ }^{\star} \chi^{2}=9.66, \mathrm{p}<0.05 ;{ }^{\star \star} \chi^{2}=13.97, \mathrm{p}<0.01 ;{ }^{\star \star \star} \chi^{2}=16.01, \mathrm{p}<0.001$ and/or Whartin Starry for the histological assessment of $H$ pylori infection.

DNA was extracted from frozen gastric juice obtained from patients with benign gastroduodenal diseases and from frozen tissue samples of patients with gastric adenocarcinoma, following the standard phenol chloroform technique as previously described. ${ }^{29}$ Using the polymerase chain reaction, the following $H$ pylori genes were studied: urease $\mathrm{A}$ (ure $A$ ) with the primers URE1 (5'GACATCACTATCAACGAAGG3') and URE2 (5'TGAAAACCACGCTCTTTAG3') ${ }^{29}$; cag $A$ with the primers HPC1 (5'TCAAATACACCAACGCCTCC3') and HPC2 (5'AGCTTCTTGTGGGGACAATC3'), constructed using a specific PC program (Primer, version 0.5, Whithead Institute for Biomedical Research, Cambridge, USA); and the polymorphism of vacA with the primers VA1-F, VA1-R, VA3-F, VA3-R, VA4-F, and VA4-R under the conditions described by Atherton et al. ${ }^{26}$

From each fasting patient a serum sample was obtained for the determination of total anti- $H$ pylori antibodies (ELISA procedure) and western blotting. Both tests were performed using commercial kits supplied by Alifax (Padova, Italy) and Arnika (Milano, Italy) respectively. The antigen used for the ELISA determination of anti-H pylori antibodies was obtained from lysed bacteria and comprised more than 20 epitopes. The latter was achieved using the $H$ pylori strain ATCC 43504 antigens first electrophoresed on sodium dodecyl sulphate polyacrylamide and then transferred onto nitrocellulose strips. Diluted sera were incubated with the strips; after washing, an anti-IgG alkaline phosphatase conjugated antibody and the corresponding substrate were added. The coloured end products, evidenced as stained bands, corresponded to the antigen-antibody complexes.

Data were analysed by the $\chi^{2}$ test, analysis of variance (one way ANOVA), and Bonferroni's test for pairwise comparisons.

\section{Results}

We studied patients with gastric adenocarcinoma and compared them with four groups of patients with benign gastroduodenal diseases (gastric ulcer, duodenal ulcer, antral gastritis, and duodenitis). The mean age of patients with gastric adenocarcinoma (66 (SEM 3) years) was significantly higher than that of patients with duodenal ulcer (51 (2) years), antral gastritis (52 (3) years), or duodenitis (47 (5) years), but not that of patients with benign gastric ulcer (60 (3) years) (one way ANOVA: $F=5.6, p<0.001$ ).

In agreement with the histological assessment, the ureA gene was found in all patients with benign gastroduodenal diseases, thus confirming the presence of $H$ pylori infection. In patients with gastric adenocarcinoma the histological assessment of $H$ pylori was not available and, to diagnose the infection, we evaluated the results of the polymerase chain reaction, which was performed in two tissue samples: one from the tumour mass and another from the adjacent non-neoplastic mucosa. In these patients the results of the polymerase chain reaction obtained in the neoplastic samples were identical 


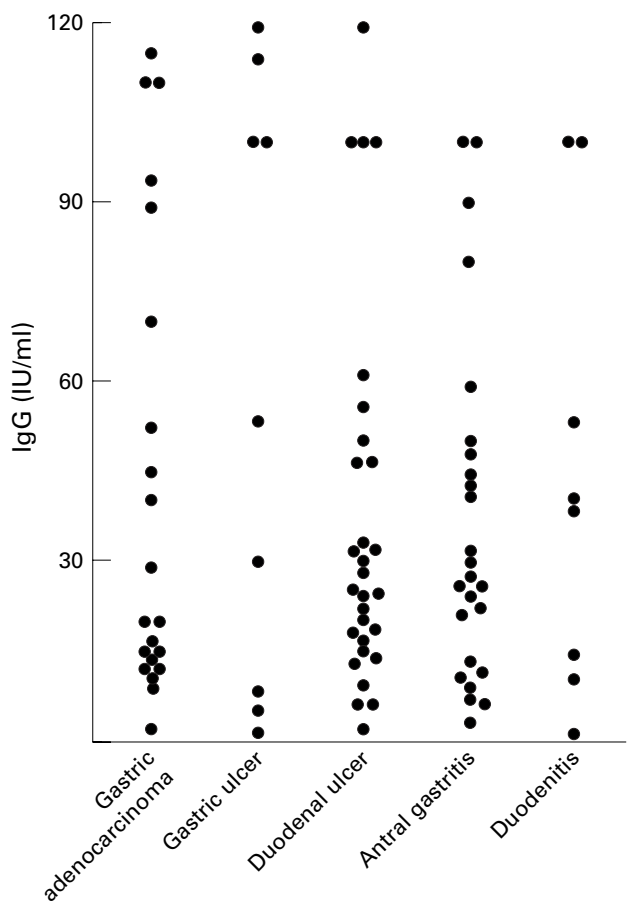

Figure 1 Individual values of anti-H pylori antibodies.

to those obtained in the adjacent nonneoplastic mucosa: ure $A$ was found in $17 / 21$ $(81 \%)$ cases.

Table 1 shows the cag $A$ gene and vac $A$ polymorphism in patients with benign diseases and those with gastric adenocarcinoma who were positive for ureA. $\operatorname{cag} A$ and the alleles s1 and $\mathrm{m} 1$ of vacA were significantly less frequent, while the alleles $\mathrm{s} 2$ and $\mathrm{m} 2$ of $v a c A$ were significantly more frequent in patients with antral gastritis than in any of the other patient groups.

Figure 1 shows the serum anti- $H$ pylori antibodies levels found in our material. No significant difference was found between the five studied groups (one way ANOVA: $F=0.98$, NS). Four patients belonging to the gastric adenocarcinoma group were $H$ pylori negative and had values for anti- $H$ pylori antibodies of 2 , 9,12 , and $52 \mathrm{IU} / \mathrm{ml}$. Considering that the cut off limit for this method, calculated on a large series of $H$ pylori negative subjects, is $10 \mathrm{IU} / \mathrm{ml}$, the sensitivity in the present series was $84 \%$.

Overall analysis of western blots showed that at least 22 bands were present with molecular weights ranging from $24 \mathrm{kDa}$ to $136 \mathrm{kDa}$. Only four antigens were known (CagA, VacA, UreB, and UreA of $136 \mathrm{kDa}, 86 \mathrm{kDa}, 66 \mathrm{kDa}$, and 26 $\mathrm{kDa}$ respectively); the nature of the others was not identified.

Table 2 shows the percentage of positive cases for each band after subdividing the patients on the basis of diagnosis.

\section{Discussion}

Our main aim was to ascertain whether there was an association between $H$ pylori specific genotype pattern and malignancy. Seventy one $H$ pylori positive patients with benign gastroduodenal diseases were compared with 21 patients with gastric adenocarcinoma. Seventeen $(81 \%)$ of the latter were found to have $H$ pylori infection, confirming previous data on the high frequency of $H$ pylori infection in patients with gastric adenocarcinoma, especially when the bacterium is investigated in surgical samples, as in our study. ${ }^{4}{ }^{10} 3031$ Of the four $H$ pylori negative patients with gastric adenocarcinoma, two had a tumour of the upper third of the stomach, which may have a non- $H$ pylori associated aetiology. Both the neoplastic and the non-neoplastic mucosal samples from $H$ pylori infected adenocarcinoma patients were positive for $H$ pylori (polymerase chain reaction). The high frequency of positive results in neoplastic samples, partly in disagreement with previous data, ${ }^{30}$ may have depended on the different methods used to identify this bacterium: we used the polymerase chain reaction which has a high sensitivity and may therefore significantly enhance the detection rate of histology. ${ }^{29}$ How-

Table 2 Percentage of positive cases for each band detected by western blotting. Patients were considered overall and on the basis of the diagnosis

\begin{tabular}{|c|c|c|c|c|c|c|c|}
\hline & Antigen $(k D a)$ & Total & $\begin{array}{l}\text { Gastric ulcer } \\
(n=9)\end{array}$ & $\begin{array}{l}\text { Duodenal ulcer } \\
(n=29)\end{array}$ & $\begin{array}{l}\text { Antral gastritis } \\
(n=25)\end{array}$ & $\begin{array}{l}\text { Duodenitis } \\
(n=8)\end{array}$ & $\begin{array}{l}\text { Gastric } \\
\text { adenocarcinoma } \\
(n=21)\end{array}$ \\
\hline 1 & $136(\mathrm{cag} A)$ & 85 & 78 & 97 & 68 & 100 & 86 \\
\hline 2 & $86(\operatorname{vac} A)$ & 48 & 44 & 55 & 40 & 63 & 43 \\
\hline 3 & 74 & 41 & 44 & 45 & 56 & 50 & $14^{\star}$ \\
\hline 4 & 70,5 & 49 & 33 & 38 & 60 & 88 & 43 \\
\hline 5 & 66 (ureB) & 52 & 44 & 45 & 56 & 50 & 62 \\
\hline 6 & 59 & 76 & 67 & 72 & 88 & 63 & 76 \\
\hline 7 & 55 & 100 & 100 & 100 & 100 & 100 & 100 \\
\hline 8 & 50 & 79 & 88 & 69 & 84 & 88 & 86 \\
\hline 9 & 45 & 26 & 11 & 34 & 32 & 13 & 19 \\
\hline 10 & 43,5 & 40 & 33 & 48 & 40 & 38 & 33 \\
\hline 11 & 43 & 41 & 33 & 41 & 56 & 50 & 24 \\
\hline 12 & 41,5 & 39 & 22 & 38 & 64 & 25 & 24 \\
\hline 13 & 37 & 7 & 13 & 3 & 1 & 11 & 5 \\
\hline 14 & 35 & 3 & 0 & 7 & 4 & 0 & 0 \\
\hline 15 & 33 & 4 & 0 & 10 & 0 & 11 & 0 \\
\hline 16 & 32 & 2 & 0 & 7 & 0 & 0 & 0 \\
\hline 17 & 30 & 25 & 11 & 24 & 32 & 25 & 24 \\
\hline 18 & 28 & 6 & 13 & 7 & 4 & 13 & 5 \\
\hline 19 & 26 (ureA) & 63 & 89 & 48 & 68 & 75 & 62 \\
\hline 20 & 25,5 & 39 & 67 & 34 & 32 & 63 & 33 \\
\hline 21 & 24,5 & 9 & 11 & 7 & 12 & 13 & 5 \\
\hline 22 & 24 & 76 & 56 & 72 & 88 & 63 & 81 \\
\hline
\end{tabular}

${ }^{\star} \chi^{2}=4.13, \mathrm{p}<0.05$. 
ever, the ability to detect $H$ pylori by polymerase chain reaction from gastric adenocarcinoma specimens may be because these are contaminated with gastric juice, and does not necessarily imply direct colonisation of gastric adenocarcinoma by $H$ pylori.

One of the major virulence factors of $H$ pylori is an $86 \mathrm{kDa}$ protein, a vacuolating cytotoxin, which can induce cell vacuolisation. ${ }^{25}$ This protein is coded by the polymorphic vacA gene: the $\mathrm{s} 1$ sequence of the region encoding the signal peptide and the $\mathrm{ml}$ of the mid portion of the gene are associated with a high cytotoxicity. Sequences $\mathrm{s} 2$ and $\mathrm{m} 2$ are found in non-cytotoxic strains, while the $\mathrm{s} 1$ and $\mathrm{m} 2$ combination is associated with moderate cytotoxicity. ${ }^{2526}$

Furthermore, unlike non-cytotoxic strains, the vast majority of cytotoxic $H$ pylori strains have the $\operatorname{cag} A$ gene. ${ }^{25} 26$ A large number of studies have shown the association between CagA positive serology and peptic ulcer disease $^{252832}$ and gastric cancer. ${ }^{12}{ }^{14}$ In agreement, cag $A$ gene, assessed by polymerase chain reaction, was found to be associated with ulcer status. ${ }^{32-34}$ Further studies have assessed the association between vacA genotype and benign gastroduodenal pathologies, showing the association between the alleles $\mathrm{s} 1$ and $\mathrm{m} 1$ and peptic ulceration. ${ }^{32}{ }^{35}$ In this study we found a significant association between cagA and the alleles $\mathrm{s} 1$ and $\mathrm{m} 1$ of vacA and diseases of either a neoplastic or non-neoplastic nature, in particular gastric and duodenal ulcer and gastric adenocarcinoma. This finding, in agreement with previous data, ${ }^{25}{ }^{26}{ }^{32-34}$ indicates that $H$ pylori cytotoxin plays a role in promoting the development of severe mucosal damage, although it does not seem to be singly involved in the pathophysiological cascade leading to gastric adenocarcinoma. Furthermore, the higher mean age of patients with gastric adenocarcinoma suggests that long persistence of $H$ pylori infection together with long exposure periods to different carcinogens are probably involved in the pathogenesis of gastric cancer.

The carcinogenic effect of $H$ pylori probably depends not only on its ability to produce the vacuolating cytotoxin, but also on other virulence factors. We therefore evaluated the serological pattern of antibodies elicited against $H$ pylori antigens by means of western blotting. Twenty two bands of different molecular weights were clearly identified. Of these only four have been defined in nature: CagA of $136 \mathrm{kDa}$, VacA of $86 \mathrm{kDa}$, Urease $\mathrm{B}$ of $66 \mathrm{kDa}$, and Urease A of $26 \mathrm{kDa}$. The serological pattern of anti-CagA antibodies in patients with benign or malignant diseases confirmed the above mentioned findings on the $H$ pylori genotype; in particular, positive findings were highly frequent in patients with gastric or duodenal ulcer and in those with gastric adenocarcinoma. Anti-VacA were found less frequently than anti-CagA; this discrepancy is probably due to the different immunogenetic properties of vacuolating cytotoxin with respect to the CagA protein. ${ }^{25}$
In patients with gastric adenocarcinoma the antibodies against the $74 \mathrm{kDa}$ band were less frequent than in patients with benign diseases. However, a modified antibody response to $H$ pylori in patients with gastric adenocarcinoma has recently been described: an increased frequency in the antibody response to a $45 \mathrm{kDa}$ $H$ pylori antigen was reported by Mitchell et $a l,{ }^{13}$ and a reduced antibody response to 33 and $66 \mathrm{KDa} H$ pylori antigens was reported by Klaamas et al. ${ }^{36}$

The final observation regarding western blotting results concerns the absolute sensitivity of the antibody, anti-55 $\mathrm{kDa} H$ pylori antigen, which was found in all $\mathrm{H}$ pylori positive cases. This sensitivity largely overcomes that of the routine determination of anti-H pylori antibodies ( $84 \%$ in the present series). Preliminary results indicate that in $H$ pylori negative subjects the anti- $55 \mathrm{kDa}$ antibody is rarely found (3/18), suggesting that it also has a good specificity $(83 \%)$. If this is confirmed in large series, this antibody might have significant diagnostic advantages in the assessment of $H$ pylori infection.

Filippo Navaglia is supported by a fellowship from the Associazione Italiana per la Ricerca sul Cancro.

1 Correa P. Human gastric carcinogenesis: a multistep and multifactorial process-First American Cancer Society Award Lecture on Cancer Epidemiology and Prevention. Award Lecture on Cancer Epid

2 Hansson L-E, Engstrand L, Nyren O, et al. Helicobacter pylori infection: independent risk indicator of gastric adenocarcinoma. Gastroenterology 1993;105:1098-103.

3 Nightingale TE, Gruber J. Helicobacter and human cancer. 7 Natl Cancer Inst 1994;86:148-52.

4 Asaka M, Kimura T, Kato M, et al. Possible role of Helicobacter pylori infection in early gastric cancer development. Cancer 1994;73:2691-4.

5 Hwang H, Dwyer J, Russel RM. Diet, Helicobacter pylori infection, food preservation and gastric cancer risk: are there new roles for preventative factors? Nutr Rev 1994;52: $75-83$.

6 Craanen ME, Blok P, Dekker W, et al. Helicobacter pylori and early gastric cancer. Gut 1994;35:1372-4.

7 Kuipers EJ, Meuwissen SGM. Helicobacter pylori and gastric carcinogenesis. Scand $\mathcal{f}$ Gastroenterol 1996;31(suppl 218): 103-5.

8 Forman D. Helicobacter pylori and gastric cancer. Scand $\mathcal{F}$ Gastroenterol 1996;31(suppl 220):23-6.

Gastroenterol 1996;31 (suppl 220):23-6.
Nedrud JG, Czinn SJ. Helicobacter pylori. Curr Opin Nedrud JG, Czinn SJ. He
Gastroenterol 1997;13:71-8.

10 Hirai M, Azuma T, Ito S, et al. High prevalence of neutralizing activity to Helicobacter pylori cytotoxin in serum of gastric carcinoma patients. Int $\mathcal{F}$ Cancer 1994;56:56-60.

11 Blaser MJ, Chyou PH, Nomura A. Age at establishment of Helicobacter pylori infection and gastric carcinoma, gastric ulcer, and duodenal ulcer risk. Cancer Res 1995;55:562-5.

12 Blaser MJ, Perez-Perez GI, Kleanthous $\mathrm{H}$, et al. Infection with Helicobacter pylori strains possessing cagA is associated with an increased risk of developing adenocarcinoma of the stomach. Cancer Res 1995;55:2111-15.

13 Mitchell HM, Hazell SL, Li YY, et al. Serological response to specific Helicobacter pylori antigens: antibody against cagA antigen is not predictive of gastric cancer in a developing country. Am f Gastroenterol 1996;91:1785-8.

14 Parsonnet J, Friedman GD, Orentreich N, et al. Risk for gastric cancer in people with CagA positive or CagA negagastric cancer in people with CagA positive or CagA nega-
tive Helicobacter pylori infection. Gut 1997;40:297-301.

15 Brenes F, Ruiz B, Correa P, et al. Helicobacter pylori causes hyperproliferation of the gastric epithelium: pre- and posteradication indices of proliferating cell nuclear antigen. $\mathrm{Am}$ 7 Gastroenterol 1993;88:1870-5.

6 Vollmers HP, Dammrich J, Ribbert H, et al. Human monoclonal antibodies from stomach carcinoma patients react with Helicobacter pylori and stimulate stomach cancer cells in vitro. Cancer 1994;74:1525-32.

17 Murakami K, Fujioka T, Kodama R, et al. Helicobacter pylori infection accelerates human gastric mucosal cell proliferation. F Gastroenterol 1997;32:184-8.

18 Plebani M, Basso D, Cassaro M, et al. Helicobacter pylori serology in patients with chronic gastritis. Am f Gastroenterol 1996;91:954-8.

19 Davies GR, Simmonds NJ, Stevens TRJ, et al. Helicobacter pylori stimulates antral mucosal reactive oxygen metabolite pylori stimulates antral mucosal reactive oxyg

20 Banerjee S, Hawksby C, Miller S, et al. Effect of Helicobacter pylori and its eradication on gastric juice ascorbic acid. Gut 1994;35:317-22. 
21 Baik S-C, Youn H-S, Chung M-H, et al. Increased oxidative DNA damage in Helicobacter pylori-infected human DNA damage in Helicobacter pylori-infecte

22 Labenz J, Borsch G. Evidence for the essential role of Helicobacter pylori in gastric ulcer disease. Gut 1994;35:19-22.

23 Bayerorffer E, Neubauer A, Rudolph B, et al. Regression of primary gastric lymphoma of mucosa-associated lymphoid tissue type after cure of Helicobacter pylori infection. Lan cet 1995;345:1591-4.

24 Fontham ETH, Ruiz B, Perez A, et al. Determinants of Helicobacter pylori infection and chronic gastritis. $\mathrm{Am} f$ Gastroenterol 1995;90:1094-101.

25 Cover TL. The vacuolating cytotoxin of Helicobacter pylori. Mol Microbiol 1996;20:241-6.

26 Atherton JC, Cao P, Peek RM, et al. Mosaicism in vacuolating cytotoxin alleles of Helicobacter pylori. Association of specific vacA types with cytotoxin production and peptic ulceration. F Biol Chem 1995;270:17771-7.

27 Crabtree JE, Wyatt JI, Sobala GM, et al. Systemic and mucosal humoral responses to Helicobacter pylori in mucosal humoral responses to He

28 Cover TL, Glupczynski Y, Lage AP, et al. Serologic detection of infection with cagAt Helicobacter pylori detection of infection with cagA

29 Basso D, Navaglia F, Cassaro M, et al. Gastric juice polymerase chain reaction: an alternative to histology in the diagnosis of Helicobacter pylori infection. Helicobacter 1996;1:159-61.

30 Shibata T, Imoto I, Ohuchi Y, et al. Helicobacter pylori infection in patients with gastric carcinoma in biopsy an surgical resection specimens. Cancer 1996;77:1044-9.

31 Shibata T, Imoto I, Gabazza EC. Detection of Helicobacter pylori in biopsy of patients with gastric carcinoma. Biomed Pharmacother 1997;51:22-8.

32 Navaglia F, Basso D, Piva MG, et al. Helicobacter pylori cytotoxic genotype is associated with peptic ulcer and cytotoxic genotype is associated with peptic ulcer an
influences serology. Am $\mathcal{f}$ Gastroenterol 1998;93:227-30.

33 Peek RM, Miller GG, Tham KT, et al. Heightned inflammatory response and cytokine expression in vivo to cagA Helicobacter pylori strains. Lab Invest 1995;71:760-70.

34 Yamaoka Y, Kita M, Kodama T, et al. Helicobacter pylori cagA gene and expression of cytokine messenger RNA in gastric mucosa. Gastroenterology 1996;110:1744-52.

35 Atherton JC, Peek RM, Tham KT, et al. Clinical and pathological importance of heterogeneity in vacA, the vacuolating cytotoxin gene of Helicobacter pylori. Gastroenterology 1997;112:92-9.

36 Klaamas $\mathrm{K}$, Held $\mathrm{M}$, Wadstrom $\mathrm{T}$, et al. IgG immune response to Helicobacter pylori antigens in patients with gastric cancer as defined by ELISA and immunoblotting. Int $\mathcal{F}$ Cancer 1996;67:1-5. 